\title{
Attitudes and Awareness of Diabetic Patients in Kuwait Towards Their Oral Health
}

\author{
Monera Alhuwais ${ }^{1 *}$, Afnan Alkanderi ${ }^{1}$ and Bobby Jospeh ${ }^{2}$
}

${ }^{1}$ Faculty of Dentistry, Kuwait University, Kuwait

${ }^{2}$ Department of Diagnostic Sciences, Faculty of Dentistry, Kuwait University, Kuwait

*Corresponding author: Monera Alhuwais, Faculty of Dentistry, Kuwait University, Jabriya, Kuwait, Tel: +96599560652

\begin{abstract}
Objectives: The main aim of this study was to demonstrate the awareness and attitudes of diabetic patients in Kuwait towards their oral health and to educate these patients to maintain a better oral health-related quality of life.

Methods: This is a cross-sectional study done through an anonymous questionnaire randomly distributed to adult diabetic patients attending the Ministry of Health $(\mathrm{MOH})$ diabetic clinics and Kuwait University Dental Center (KUDC). The questionnaire included socio-demographic characteristics, the patient's awareness about the relationship between diabetes and systemic diseases, and the relationship between diabetes and oral health, as well as the patient's attitudes towards oral health.

Results: A total of 206 diabetic patients participated in this study. Results show that more than $75 \%$ of the patients were aware of the association of diabetes on general health, whereas more than $60 \%$ were aware of the effect of diabetes on oral health. Regarding the attitudes towards oral health, more than $50 \%$ of the participants visit the dentist when in pain, the majority brush their teeth at least once a day, and most of them do not floss nor use mouthwash.

Conclusion: Diabetic patient's level of knowledge about the effect of diabetes mellitus on their general and dental health was found to be good. However, general health awareness was higher than dental health awareness. Hence awareness and association between diabetes and oral health need to be improved in diabetic patients.
\end{abstract}

\section{Keywords}

Attitudes, Awareness, Diabetic patients, Kuwait, Oral health

\section{Abbreviations}

$\mathrm{MOH}$ : Ministry of Health; KUDC: Kuwait University Dental Center; DM: Diabetes Mellitus; IDF: International Diabetes Federation; SPSS: Statistical Package for Social Science; KSA: Kingdom of Saudi Arabia

\section{Introduction}

Diabetes mellitus (DM) is a group of metabolic diseases characterized by hyperglycemia resulting from defects in insulin secretion, insulin action, or both. Type 1 diabetes is characterized by decreased secretion of insulin due to autoimmune or idiopathic destruction of the B-cells in the pancreas. It usually occurs in younger populations; however, it can be found in any age [1-4]. Type 2 diabetes, which is more common, is characterized by insulin resistance in peripheral tissues, usually in combination with decreased insulin secretion. It presents in middle and older aged individuals; however, it may exist in younger individuals who are overweight [1,4-6]. According to the International Diabetes Federation (IDF), Kuwait is the sixth country with the highest prevalence of diabetes [7]. The adjusted prevalence of diabetes in Kuwait is 19.1\% [8].

It is well knownthatDMcan irreversiblyaffect different systems of the body resulting in several complications, which can be broadly categorized into macrovascular and microvascular complications. Morbidity and mortality associated with diabetes are mostly due to macrovascular complications, which in turn may lead to coronary artery disease, cerebrovascular, and peripheral vascular disease $[4,9]$. Strokes are twice more likely to occur in diabetic patients, and they are three to five times at risk of developing myocardial infarctions $[4,10]$. The microvascular complications include retinopathy, nephropathy, and neuropathy. Cataract and blindness are the most significant complications of retinopathy, and kidney failure is the number one cause of premature death in diabetic patients. Neuropathy causes axon

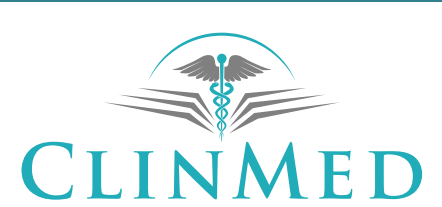

INTERNATIONAL LIBRARY

Citation: Alhuwais M, Alkanderi A, Jospeh B (2021) Attitudes and Awareness of Diabetic Patients in Kuwait Towards Their Oral Health. Int J Oral Dent Health 7:133. doi.org/10.23937/2469-5734/1510133 Accepted: September 04, 2021: Published: September 06, 2021

Copyright: (C) 2021 Alhuwais M, et al. This is an open-access article distributed under the terms of the Creative Commons Attribution License, which permits unrestricted use, distribution, and reproduction in any medium, provided the original author and source are credited. 
demyelination, which leads to disruption of sensation and diabetic foot [10].

Diabetes mellitus can have many oral manifestations. Xerostomia, or dry mouth, is one of the common manifestations, and its exact cause is unknown, but it can be associated with dysfunction of the salivary glands. Furthermore, hyperglycemia results in more viscous saliva $[4,11,12]$. Xerostomia, along with increased salivary glucose content, may lead to an increased risk of developing dental caries $[4,13]$. Moreover, diabetic patients are more prone to oral infections due to the effect of hyperglycemia on the immune system, leading to immunosuppression. Of these oral infections, oral candidiasis is one of the most common, as well as glossitis, angular cheilitis, and burning mouth syndrome $[4,11,14,15]$. Another major oral complication of diabetes is periodontal disease, including gingivitis and periodontitis. There is a dual relationship between diabetes and periodontal disease, as studies show that diabetes can lead to periodontal disease, and periodontal disease can affect the control of diabetes $[11,16]$. A review paper on "Diabetes mellitus and Oral Health" [10], also showed a strong association between diabetes mellitus and oral health.

Both type 1 and type 2 diabetes can result in periodontitis [17], and studies show that diabetic patients are three times more likely to develop periodontitis $[11,18]$. Controlled diabetics are at a lower risk of developing periodontitis compared to uncontrolled diabetics $[11,19,20]$.

Based on the literature review, we found that some of the studies included diabetic patients and their attitudes and awareness towards oral health. However, none of the studies were conducted in Kuwait. Hence, investigating the attitude in diabetic patients towards dental health and determining the importance of oral health on quality of life within this group were the main aims of this study.

\section{Subjects and Methods}

Our study is a cross-sectional study done through an anonymous questionnaire randomly distributed to adult diabetic patients above the age of 18 . Intellectually disabled individuals and patients below the age of 18 were excluded from this study. Before proceeding with the study, approval by the Ethical Review Committee of Kuwait University, Faculty of Dentistry, was obtained. A consent form was attached to the questionnaire, and the reasons for the study were explained to the participants. The surveys were distributed to diabetic patients attending the Ministry of Health $(\mathrm{MOH})$ diabetic clinics in the six governorates of Kuwait and Kuwait University Dental Center (KUDC). The questionnaire was divided into four parts, which included sociodemographic variables, the patient's awareness about the relationship between diabetes and systemic diseases, and the relationship between diabetes and oral health, as well as the patient's attitudes towards oral health. An informative paper on diabetes and general oral health was attached to the questionnaire. It helped educate the patients on the effect of diabetes and how to maintain a better quality of oral health by giving them oral hygiene instructions. Three-hundred eighty-four questionnaires were distributed, of which 206 patients returned the completed questionnaire. Data was collected in 2018 over a period of 6 months. The collected data were analyzed through the Statistical Package for Social Science software (SPSS), version 25. Statistical significance was set at $p<0.05$. A score of one was given for each correct answer in general and dental awareness, with a total score out of 7 for general awareness and out of 8 for dental awareness.

Table 1: Sociodemographic characteristics.

\begin{tabular}{|c|c|c|}
\hline Patient characteristics & Number & Percentage \\
\hline \multicolumn{3}{|l|}{ Gender } \\
\hline Male & 124 & $60.2 \%$ \\
\hline Female & 82 & $39.8 \%$ \\
\hline \multicolumn{3}{|l|}{ Age (years) } \\
\hline $18-35$ & 18 & $8.7 \%$ \\
\hline $36-55$ & 118 & $57.3 \%$ \\
\hline$>55$ & 70 & $34 \%$ \\
\hline \multicolumn{3}{|l|}{ Nationality } \\
\hline Kuwaiti & 103 & $50 \%$ \\
\hline Non-Kuwaiti & 103 & $50 \%$ \\
\hline \multicolumn{3}{|l|}{ Education } \\
\hline High school or < & 123 & $59.7 \%$ \\
\hline University & 76 & $36.9 \%$ \\
\hline Higher education & 7 & $3.4 \%$ \\
\hline \multicolumn{3}{|l|}{ Income } \\
\hline$<500$ & 76 & $36.9 \%$ \\
\hline $500-1,500$ & 94 & $45.6 \%$ \\
\hline$>1,500-2,000$ & 26 & $12.6 \%$ \\
\hline$>2,000$ & 10 & $4.9 \%$ \\
\hline \multicolumn{3}{|l|}{ Type of diabetes } \\
\hline Type 1 & 21 & $10.2 \%$ \\
\hline Type 2 & 154 & $74.8 \%$ \\
\hline I don't know & 31 & $15 \%$ \\
\hline \multicolumn{3}{|l|}{ Diabetes status } \\
\hline Controlled & 160 & $77.7 \%$ \\
\hline Uncontrolled & 46 & $22.3 \%$ \\
\hline \multicolumn{3}{|l|}{ Medications } \\
\hline Yes & 186 & $90.3 \%$ \\
\hline No & 20 & $9.7 \%$ \\
\hline \multicolumn{3}{|c|}{ Duration of diabetes (years) } \\
\hline $1-5$ & 92 & $44.7 \%$ \\
\hline $5-10$ & 61 & $29.6 \%$ \\
\hline$>10$ & 53 & $25.7 \%$ \\
\hline
\end{tabular}




\section{Results}

A total of 206 patients participated in this study. Of these participants, 124 (60.2\%) were males, and 82 (39.8\%) were females. The median age of the participating diabetic patients was 52 years, and the mean age was 51.3 years.

Table 1 shows the sociodemographic characteristics of the participants. With regards to nationality, Kuwaitis were $50 \%$, and Non-Kuwaitis were $50 \%$ of the included population. The majority $(59.7 \%)$ had a high school level of education or less, whereas a minority (3.4\%) had a higher level of education. About the types of diabetes mellitus, $10.2 \%$ of the participants had type $1,74.8 \%$ had type 2 , and $15 \%$ did not know the type of diabetes they had. Around $77.7 \%$ of the participants had controlled diabetes, and more than $90 \%$ were taking their medication regularly. As for the duration of diabetes, $44.7 \%$ of them were diagnosed within the last five years.

From each of the six governorates of Kuwait, 3040 patients participated. The patients attending KUDC were $10.2 \%$ of the total participants in this study.

Regarding the knowledge of the study participants about the complications of diabetes mellitus on the different systems of the body, Table 2 shows that more than $75 \%$ of the study patients were aware of the effect of DM on the eyes, heart, kidneys, nerves, and foot, as well as its relation to thirst and urination. The two complications that the participants were most aware of are the effect of DM on the eyes (90.3\%) and foot $(90.8 \%)$.
Table 3 shows that more than $60 \%$ of diabetic patients are aware of the effect of DM on oral health. The complications the patients were mainly aware of are the effect of DM on general oral health $(79.1 \%)$ and that it can cause an increased risk of tooth loss (75.2\%); however, the participants were least aware of the increased risk of caries $(29.6 \%)$ and increased gingival bleeding (29.1\%).

Table 4 shows the attitudes of the study population towards oral health. The minority (28.6\%) of the participants are smokers. When they have oral problems, the majority $(73.8 \%$ ) visit a dentist, while $18 \%$ said they would visit a doctor, $5.8 \%$ self-treat, and $2.4 \%$ would ignore it. Regarding the frequency of visits to the dentist, $52.9 \%$ of the participants visit the dentist when in pain, and only $19.9 \%$ visit the dentist biannually. As for the frequency of brushing, $40.3 \%$ of the study population brush once a day and $70.9 \%$ use fluoridated toothpaste. Most of the participants never floss (61.2\%) or use mouthwash (54.4\%).

Table 5 shows the association between education and both general and dental awareness. The mean score of dental awareness for patients with a higher education level $(6.9 \pm 0.4)$ was found to be significantly higher than other educational backgrounds ( $p$-value of 0.005).

Table 6 demonstrates the association between KUDC patients and both general and dental awareness. Diabetic KUDC patients were more aware of their oral health compared to non-KUDC patients. The dental awareness mean score for KUDC patients $(6.9 \pm 2)$ was recorded to be significantly higher ( $p$-value 0.001 ).

Table 2: Awareness of the effect of diabetes on the systems of the body.

\begin{tabular}{|l|l|l|l|}
\hline & Yes & No & I don't know \\
\hline Effect of DM on the eyes & $186(90.3 \%)$ & $10(4.9 \%)$ & $10(4.9 \%)$ \\
\hline Effect of DM on the heart & $160(77.7 \%)$ & $15(7.3 \%)$ & $31(15 \%)$ \\
\hline Effect of DM on the kidneys & $170(82.5 \%)$ & $14(6.8 \%)$ & $22(10.7 \%)$ \\
\hline Effect of DM on the nerves & $175(85 \%)$ & $10(4.9 \%)$ & $21(10.2 \%)$ \\
\hline Effect of DM on the foot & $187(90.8 \%)$ & $9(4.4 \%)$ & $10(4.9 \%)$ \\
\hline DM increases thirst & $180(87.4 \%)$ & $13(6.3 \%)$ & $13(6.3 \%)$ \\
\hline DM increases urination frequency & $180(87.4 \%)$ & $11(5.3 \%)$ & $15(7.3 \%)$ \\
\hline
\end{tabular}

Table 3: Awareness of the effect of diabetes on oral health.

\begin{tabular}{|c|c|c|c|}
\hline & Yes & No & I don't know \\
\hline Smoking affects the gingiva of diabetics & $146(70.9 \%)$ & $11(5.3 \%)$ & $49(23.8 \%)$ \\
\hline DM affects general oral health & $163(79.1 \%)$ & $13(6.3 \%)$ & $30(14.6 \%)$ \\
\hline DM increases gingival bleeding & $129(62.6 \%)$ & $17(8.3 \%)$ & $60(29.1 \%)$ \\
\hline DM affects healing of oral wounds/ulcers & $154(74.8 \%)$ & $8(3.9 \%)$ & $44(21.4 \%)$ \\
\hline DM causes ketone breath & $136(66 \%)$ & $16(7.8 \%)$ & $54(26.2 \%)$ \\
\hline DM can cause tooth loss & $155(75.2 \%)$ & $13(6.3 \%)$ & $38(18.4 \%)$ \\
\hline DM increases risk of oral infections & $145(70.4 \%)$ & $15(7.3 \%)$ & $46(22.3 \%)$ \\
\hline DM increases risk of caries & $129(62.6 \%)$ & $16(7.8 \%)$ & $61(29.6 \%)$ \\
\hline
\end{tabular}


Table 4: Attitudes towards oral health.

\begin{tabular}{|c|c|c|}
\hline & Number & Percentage \\
\hline \multicolumn{3}{|c|}{ Smoking } \\
\hline Yes & 59 & $28.6 \%$ \\
\hline No & 147 & $71.4 \%$ \\
\hline
\end{tabular}

Action taken when having oral problems

\begin{tabular}{|l|l|l|}
\hline Visit a doctor & 37 & $18 \%$ \\
\hline Visit a dentist & 152 & $73.8 \%$ \\
\hline Self-treat & 12 & $5.8 \%$ \\
\hline Ignore it & 5 & $2.4 \%$ \\
\hline
\end{tabular}

\section{Visits to the dentist}

\begin{tabular}{|l|l|l|}
\hline Every 3 months & 23 & $11.2 \%$ \\
\hline Every 6 months & 41 & $19.9 \%$ \\
\hline Once a year & 24 & $11.7 \%$ \\
\hline When in pain & 109 & $52.9 \%$ \\
\hline Never & 9 & $4.4 \%$ \\
\hline
\end{tabular}

\section{Brushing frequency}

\begin{tabular}{|l|l|l|}
\hline After meals & 32 & $15.5 \%$ \\
\hline Twice a day & 79 & $38.3 \%$ \\
\hline Once a day & 83 & $40.3 \%$ \\
\hline Never & 12 & $5.8 \%$ \\
\hline
\end{tabular}

\section{Fluoridated toothpaste}

\begin{tabular}{|l|l|l|}
\hline Yes & 146 & $70.9 \%$ \\
\hline No & 21 & $10.2 \%$ \\
\hline I don't know & 39 & $18.9 \%$ \\
\hline
\end{tabular}

\section{Flossing frequency}

\begin{tabular}{|l|l|l|}
\hline Twice a day & 25 & $12.1 \%$ \\
\hline Once a day & 24 & $11.7 \%$ \\
\hline $1-3$ a week & 31 & $15 \%$ \\
\hline Never & 126 & $61.2 \%$ \\
\hline
\end{tabular}

\section{Mouthwash frequency}

\begin{tabular}{|l|l|l|}
\hline Twice a day & 31 & $15 \%$ \\
\hline Once a day & 35 & $17 \%$ \\
\hline $1-3$ a week & 28 & $13.6 \%$ \\
\hline Never & 112 & $54.4 \%$ \\
\hline
\end{tabular}

Table 5: Education and awareness.

\begin{tabular}{|c|c|c|}
\hline & $\begin{array}{l}\text { General awareness } \\
\text { mean score (SD) }\end{array}$ & $\begin{array}{l}\text { Dental awareness } \\
\text { mean score (SD) }\end{array}$ \\
\hline \multicolumn{3}{|l|}{ Education } \\
\hline Highschool or < & $5.9(1.7)$ & $5.1(2.8)$ \\
\hline University & $6.1(1.8)$ & $6.3(2)$ \\
\hline \multirow{2}{*}{$\begin{array}{l}\text { Higher } \\
\text { Education }\end{array}$} & $6.9(0.4)$ & $6.9(1.7)$ \\
\hline & $p$-value 0.22 & $p$-value 0.005 \\
\hline
\end{tabular}

*Significant $p$-value $<0.05$

\section{Discussion}

According to the International Diabetes Federation (IDF), 425 million people had diabetes in 2017, and the prevalence is expected to rise to 629 million by the year
Table 6: KUDC and awareness.

\begin{tabular}{|l|l|l|}
\hline KUDC & $\begin{array}{l}\text { General awareness } \\
\text { mean score (SD) }\end{array}$ & $\begin{array}{l}\text { Dental awareness } \\
\text { mean score (SD) }\end{array}$ \\
\hline Yes & $6(1.5)$ & $6.9(2)$ \\
\hline No & $6(1.8)$ & $5.5(2.6)$ \\
\hline & p-value 0.5 & p-value 0.001 \\
\hline
\end{tabular}

*Significant $p$-value $<0.05$

2045 [21]. In our study, $10.2 \%$ of the participants had type 1 diabetes, $74.8 \%$ had type 2 diabetes, and $15 \%$ did not know which type they had.

In one study, which focused on the relationship between periodontal disease and DM, the aim was to assess the knowledge of medical and dental practitioners [22]. However, in our study, the target population was diabetic patients who attended diabetic clinics in the $\mathrm{MOH}$ and KUDC.

Another cross-sectional study about diabetic patient's attitudes and awareness towards their oral health was done in the Kingdom of Saudi Arabia (KSA). It included several factors, such as age, type of diabetes, and duration of diabetes, as well as visits to dental clinics and other factors [23]. This study is very similar to our own; however, it was conducted in Abha City. Moreover, this study included patients below the age of 18 , while our target is patients above 18 years of age.

In our study, we wanted to assess the knowledge of diabetic patients in Kuwait about the effect of diabetes on systemic health. Results showed that $90 \%$ were aware of the risk of diabetes on the eyes, $77 \%$ on the heart, and $82 \%$ on the kidneys. These results were somewhat similar to a study done in Dubai, where $85 \%$ were aware of the risk on the eyes, $75 \%$ on the heart, and $90 \%$ on the kidneys [24]. However, in the study done in KSA, the results showed decreased general awareness in comparison with our findings [23].

Regarding awareness, patients were more aware of the systemic complications related to diabetes compared to their knowledge of oral complications. Results in the present study show that $71 \%$ of the participants recognized that diabetic smokers were more prone to gingival disease. Seventy-nine percent were aware of the effect of diabetes on general oral health, and $63 \%$ were mindful of the impact of diabetes on gingival health. With regards to oral infections and dental caries, the results were $70 \%$ and $63 \%$, respectively. In the study conducted in KSA, the results for the dental awareness were less than $50 \%$, except for the awareness about the risk of diabetic smokers developing more gingival disease compared to non-smokers, where the result was $84 \%$ [23]. As for the study done in Dubai, results for oral infections and dental caries were $42 \%$ and $54 \%$, respectively [24].

Since diabetic patients are more prone to oral diseases, it is crucial for them to maintain good oral 
hygiene and to visit the dentist regularly. In the present study, we wanted to look at the participant's attitudes towards (their general) health and to further educate them on the relation between diabetes and oral health as well as the importance of sustaining proper oral hygiene. Only $29 \%$ of the participants were smokers, and the majority (74\%) visited the dentist when they had oral problems, whereas $18 \%$ visited a general physician. As for dental visits frequency, more than $50 \%$ of the participants visit the dentist only when in pain, which was similar to the results in a study done in Ireland [25]. The majority of this study's participants brush their teeth at least once a day; however, more than half of the participants have never flossed nor used mouthwash. In the study conducted in Abha City, 18\% of the participants were smokers, $78 \%$ visited a dentist when they had oral problems, more than $60 \%$ visited the dentist once a year, and the majority brushed their teeth at least once a day [23]. The results of our study were similar to the study conducted in Dubai in that the majority of the participants visit the dentist when in pain, brush their teeth at least once daily, and more than half of them have never used dental floss [24].

\section{Conclusion}

Diabetic patient's level of knowledge about the effect of diabetes mellitus on their general and dental health was found to be good. Moreover, general health awareness was higher than dental health awareness. Regarding the attitudes of diabetic patients in Kuwait towards oral health, the overall dental practices were lacking. Therefore, it is of great importance for health care professionals, including both general physicians and dental practitioners, to provide diabetic patients with the necessary information about the impact of their condition on their health. Awareness about this issue needs to be raised through further researches as well as national campaigns that target diabetic patients, their caretakers, and families on the importance of maintaining good oral health and regular dental visits to prevent and early detect oral diseases.

\section{Acknowledgment}

We are grateful to Devi Priya for her assistance, input, and valuable information, which aided in the completion of this project.

We would also like to extend our sincere thanks and appreciation to Dr. Fatma Al-Sultan for her valuable support and contribution in completing this study.

\section{Statement of Ethics}

Prior to proceeding with the study, approval by the Ethical Review Committee of Kuwait University, Faculty of Dentistry, was obtained. A consent form was attached to the questionnaire, and the reasons for the study were explained to the participants.

\section{Disclosure Statement}

The authors have no conflicts of interest to declare.

\section{Authors Statement}

M.H. and A.K. designed the study, distributed the questionnaire, analyzed the results, and wrote the manuscript. B.J. supervised the study.

\section{References}

1. American Diabetes Association (2014) Diagnosis and classification of diabetes mellitus. Diabetes Care 37: S81-S90.

2. Wray $L$ (2011) The diabetic patient and dental treatment: An update. Br Dent J 211: 209-215.

3. Jasinski JM, Eisenbarth GS (2005) Hypothesis for the pathogenesis of type 1A diabetes. Drugs Today 41: 141-149.

4. Mohamed K, Yates J, Roberts A (2014) Diabetes mellitus: Considerations for the dental practitioner. Dent update 41: 144-154.

5. Diabetes (2007) Department of health and social care.

6. National service framework for diabetes (2010) Department of health and social care.

7. Nadine H, Abduo H, Abughefreh A, Dawwas B (2015) Diabetes Kuwait Resource Centre: Development, implementation, and offered services. GMJ 4: 8-13.

8. Alkandari A, Alarouj M, Elkum N, Sharma P, Devarajan S, et al. (2020) Adult diabetes and prediabetes prevalence in Kuwait: Data from the cross-sectional Kuwait Diabetes Epidemiology Program. J Clin Med 9: 3420.

9. Kumar P, Clark M (2005) Clinical medicine. (6 $6^{\text {th }}$ edn), Edinburgh: WB Saunders.

10. National clinical guideline for diagnosis and management in primary and secondary care. Royal College of Physicians, 2004.

11. Kudiyirickal MG, Pappachan JM (2015) Diabetes mellitus and oral health. Endocrine 49: 27-34.

12. Ship JA (2003) Diabetes and oral health: An overview. J Am Dent Assoc 134: 4-10.

13. Twetman S, Johansson I, Birkhed D, Nederfors T (2002) Caries incidence in young type 1 diabetes mellitus patients in relation to metabolic control and caries-associated risk factors. Caries Res 36: 31-35.

14. Barbara DB, Dorota ZZ, Bogna WW, Wieslaw H, Anna SK, et al. (2010) Candida-associated denture stomatitis in type 2 diabetes mellitus. Diabetes Res Clin Pract 90: 81-86.

15. Wilson RM (1986) Neutrophil function in diabetes. Diabet Med 3: 509-512.

16. Mealey BL (2006) Periodontal disease and diabetes: A twoway street. J Am Dent Assoc 137: 26-31.

17. David AA, Angela W, Pamela A, Dana TG, William CK, et al. (2012) Diabetes and oral disease: Implications for health professionals. Ann NY Acad Sci 1255: 1-15.

18. Mealey BL, Ocampo GL (2007) Diabetes mellitus and periodontal disease. Periodontol 2000 44: 127-153.

19. Moore PA, Weyant RJ, Mongelluzzo MB, Myers DE, Rossie K, et al. (1999) Type 1 diabetes mellitus and oral health: Assessment of periodontal disease. J Periodontal 70: 409417. 
20. Taylor GW, Burt BA, Becker MP, Genco RJ, Shlossman M, et al. (1998) Non-insulin dependent diabetes mellitus and alveolar bone loss progression over 2 years. J Periodontol 69: 76-83.

21. International Diabetes Federation (2017) Diabetes Atlas. ( $8^{\text {th }}$ edn).

22. Al-Khabbaz AK, Al-Shammari KF (2011) Diabetes mellitus and periodontal health: Dentists' knowledge. Med Princ Pract 20: 538-544.
23. Ismaeil F, Ali N (2013) Diabetic patients knowledge, attitude and practice toward oral health. JEP 4: 19-25.

24. Eldarrat AH (2011) Diabetic patients: Their knowledge and perception of oral health. Libyan $\mathrm{J}$ Med 6.

25. Allen EM, Ziada HM , O'Halloran D, Clerehugh V, Allen PF (2008) Attitudes, awareness and oral health-related quality of life in patients with diabetes. J Oral Rehabil 35: 218-223. 